\title{
PREPARATION AND ANTIBACTERIAL ACTIVITY UPON MICROCOCCUS LUTEUS OF DERIVATIVES OF ITURIN A, MYCOSUBTILIN AND BACILLOMYCIN L, ANTIBIOTICS FROM BACILLUS SUBTILIS
}

\author{
Françoise Peypoux, Françoise Besson, Georges Michel \\ and Lucien Delcambe* \\ Laboratoire de Biochimie Microbienne, Université Claude Bernard, Lyon I, \\ 43 Boulevard du 11 Novembre 1918, 69621 Villeurbanne, France \\ * Centre National de Production et d'Etude des Substances d'Origine Microbienne \\ (C.N.P.E.M.), 32 Boulevard de la Constitution, 4020 Liège, Belgique \\ (Received for publication September 25, 1978)

\begin{abstract}
Methylated and acetylated derivatives of iturin A and mycosubtilin and methylated derivatives of bacillomycin L were prepared and their antibacterial activity on Micrococcus luteus was compared with the activity of the original substance. The results obtained show the importance of polar groups for the antibiotic activity of the substances of iturin group.
\end{abstract}

Iturin $\mathrm{A}$, mycosubtilin and bacillomycin $\mathrm{L}$ are antibiotics which were isolated from strains of Bacillus subtilis ${ }^{1,2,3)}$. Their structures have been determined ${ }^{4,5,6)}$ : these antibiotics are cyclic peptidolipids characterized by a lipid-soluble $\beta$-aminoacid ${ }^{(j)}$ linked to a peptide which contains D and L- $\alpha$-aminoacids (Figs. 1, 2, 3). These compounds have a strong antifungal activity and a restricted antibacterial activity against some Micrococcus and Sarcina strains ${ }^{8)}$. Their action upon Micrococcus luteus has been recently reported ${ }^{9,10)}$. We prepared various derivatives of iturin A, mycosubtilin and bacillomycin $\mathrm{L}$ and studied their antibacterial activity against $M$. luteus. The aim of this work was to determine the relation between the biological activity and the structure of these antibiotics.

Fig. 1. Structure of iturin A and derivatives.

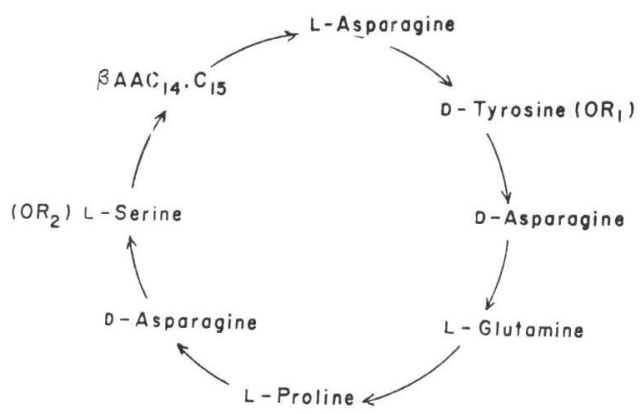

Iturin

$$
\mathbf{R}_{1}=\mathbf{R}_{2}=\mathbf{H}
$$

Compound I $\mathrm{R}_{1}=\mathrm{CH}_{3}, \mathrm{R}_{2}=\mathrm{H}$

Compound II $\mathrm{R}_{1}=\mathrm{COCH}_{3}, \mathrm{R}_{2}=\mathrm{H}$

Compound III $\mathrm{R}_{1}=\mathrm{H}, \mathrm{R}_{2}=\mathrm{COCH}_{3}$

Compound IV $\mathrm{R}_{1}=\mathrm{R}_{2}=\mathrm{COCH}_{3}$
Fig. 2. Structure of mycosubtilin and derivatives.

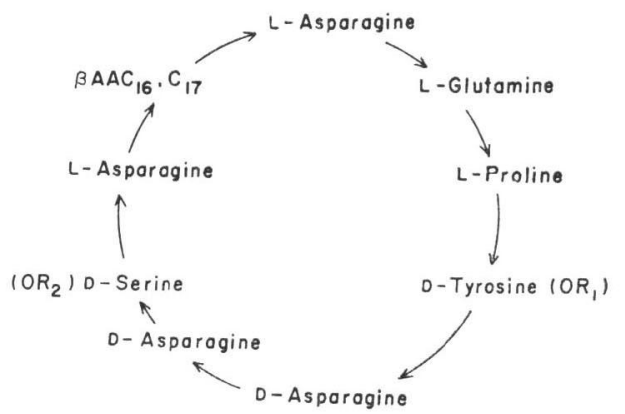

$$
\begin{array}{ll}
\text { Mycosubtilin } & \mathrm{R}_{1}=\mathrm{R}_{2}=\mathrm{H} \\
\text { Compound V } & \mathrm{R}_{1}=\mathrm{CH}_{3}, \mathrm{R}_{2}=\mathrm{H} \\
\text { Compound VI } & \mathrm{R}_{1}=\mathrm{COCH}_{3}, \mathrm{R}_{2}=\mathrm{H} \\
\text { Compound VII } & \mathrm{R}_{1}=\mathrm{H}, \mathrm{R}_{2}=\mathrm{COCH}_{3} \\
\text { Compound VIII } & \mathrm{R}_{1}=\mathrm{R}_{2}=\mathrm{COCH}_{3}
\end{array}
$$




\section{Materials and Methods}

Antibiotics.

Iturin A was prepared as described previously $^{i)}$. Mycosubtilin was a gift of Dr. H. B. Woodruff, Merck Sharp \& Dohme Research Laboratories, Rahway, New Jersey, U.S.A., and bacillomycin L was a gift of Dr. G. H. WARren, Wyeth Institute of Applied Biochemistry, West Chester, Pennsylvania, U.S.A.

\section{Preparation of Methyl Derivatives.}

The phenolic group of tyrosine of iturin A and of mycosubtilin was methylated as follows: the antibiotic $(20 \mathrm{mg})$ was dissolved in $2 \mathrm{ml}$ of anhydrous methanol and gaseous diazomethane was bubbled in the solution, for 15 minutes at $20^{\circ} \mathrm{C}$. Then the excess of diazomethane was blown out with a stream of nitrogen. This methylation gave the derivative I from iturin A and the derivative $\mathbf{V}$ from mycosubtilin. Three methyl derivatives were prepared from bacillomycin $\mathrm{L}$ as this antibiotic has two carboxylic groups and one phenolic group. Bacillomycin L (20 mg) was dissolved in $2 \mathrm{ml}$ of anhydrous methanol and treated with gaseous diazomethane for 5 minutes at $20^{\circ} \mathrm{C}$. This treatment gave a mixture of methyl diester derivative (IX) and of methyl diester O-methyl tyrosine derivative $(\mathbf{X})$. These derivatives were separated by thin-layer chromatography of the mixture on silica gel G 60 (Merck) with the solvent: chloroform-methanol-water $(65: 25: 4$, v/v/v). The O-methyl tyrosine derivative (XI) was obtained by saponification of the compound $(\mathbf{X})$ with $0.1 \mathrm{~N}$ $\mathrm{NaOH}$ for 1 hour at $60^{\circ} \mathrm{C}$.

\section{Preparation of Acetyl Derivatives.}

Iturin $\mathrm{A}$ and mycosubtilin have two hydroxyl groups, the phenolic group of tyrosine and the aliphatic hydroxyl group of serine. The O-acetyl tyrosine derivative of iturin A (II) was prepared from $20 \mathrm{mg}$ of antibiotic by a treatment with acetic anhydride - pyridine $(1: 3, \mathrm{v} / \mathrm{v})$, for 2 hours at room temperature. The esterification of the hydroxyl group of serine was very slow and the diacetyl derivative (IV) was obtained with acetic anhydride - pyridine (1: 1, v/v) in 14 days at room temperature. The diacetyl derivative of mycosubtilin (VIII) was prepared from $20 \mathrm{mg}$ of antibiotic by acetic anhydride - pyridine $(1: 3, \mathrm{v} / \mathrm{v})$ for 1 hour at room temperature. The O-acetyl serine derivatives of iturin A (III) and of mycosubtilin (VII) were prepared by mild saponification of the diacetyl derivatives $\left(0.1 \mathrm{~N} \mathrm{NaOH}\right.$ for 2 hours at $\left.60^{\circ} \mathrm{C}\right)$. The O-acetyl tyrosine derivative of mycosubtilin (VI) was obtained by acetylation with acetic anhydride - pyridine $(1: 3, \mathrm{v} / \mathrm{v})$ for 30 minutes at $0^{\circ} \mathrm{C}$.

Purification of Derivatives.

All the derivatives were purified by preparative thin-layer chromatography on silica gel $G 60$ (Merck) with the solvent A: chloroform - methanol-water $(65: 25: 4, \mathrm{v} / \mathrm{v} / \mathrm{v})$. The homogeneity of each compound was tested by TLC with the solvent $\mathrm{A}$ and with the solvent B: chloroform - dimethylformamide - water $(50: 44: 6, \mathrm{v} / \mathrm{v} / \mathrm{v})$. The revelations of the compounds were performed by spraying the plates with water and slow drying which gave white spots with peptidolipids ${ }^{11)}$; with PAULY reagent, specific of the phenolic group of tyrosine or with $\mathrm{H}_{2} \mathrm{SO}_{4} 50 \%$. The substitution of the phenolic group of tyrosine was established by a negative reaction to PAULY reagent and by U.V. spectra.

Determination of the Antibiotic Activity.

Micrococcus luteus NTCC 2665 was grown at $35^{\circ} \mathrm{C}$ on a brain-heart medium (Bio-Mérieux, France) $37 \mathrm{~g} /$ liter. After one hour $(\mathrm{OD}=0.6)$ the antibiotic was added to the medium and the growth was followed at 2 hours intervals during 10 hours by turbidimetry at $600 \mathrm{~nm}$. The percentages of 
Table 1. Rf of antibiotics and derivatives.

Solvent A: chloroform - methanol - water (65:25:4, v/v/v).

Solvent B: chloroform - dimethylformamide water $(50: 44: 6, \mathrm{v} / \mathrm{v} / \mathrm{v})$.

\begin{tabular}{c|c|c}
\hline Compound & Rf solvent A & Rf solvent B \\
\hline Iturin A & 0.35 & 0.45 \\
I & 0.50 & 0.62 \\
II & 0.50 & 0.59 \\
III & 0.52 & 0.79 \\
IV & 0.68 & 0.91 \\
\hline Mycosubtilin & 0.26 & 0.45 \\
V & 0.38 & 0.52 \\
VI & 0.38 & 0.55 \\
VII & 0.44 & 0.59 \\
VIII & 0.61 & 0.73 \\
Bacillomysin L & 0.16 & 0.38 \\
IX & 0.58 & 0.78 \\
X & 0.73 & 0.88 \\
XI & 0.22 & 0.43 \\
\hline
\end{tabular}

Fig. 5. Ultraviolet spectra of iturin A and acetyl derivatives in neutral medium (concentrations $250 \mu \mathrm{g} / \mathrm{ml})$.

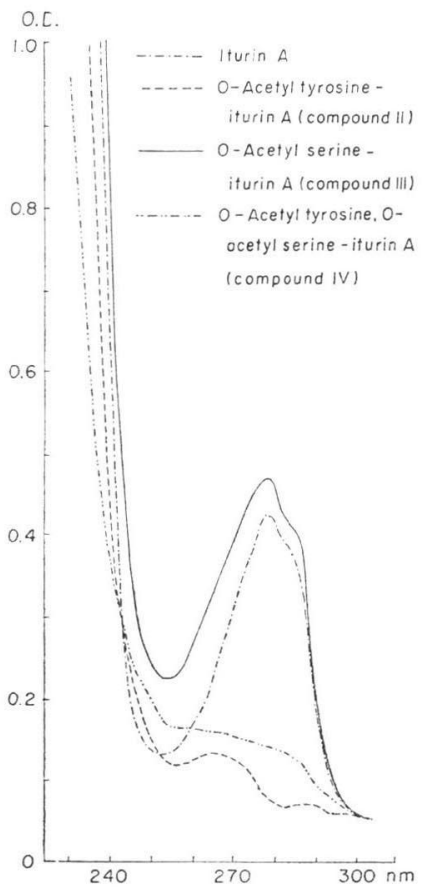

Fig. 4. Ultraviolet spectra of iturin A and methyl derivative (concentrations $250 \mu \mathrm{g} / \mathrm{ml}$ ).

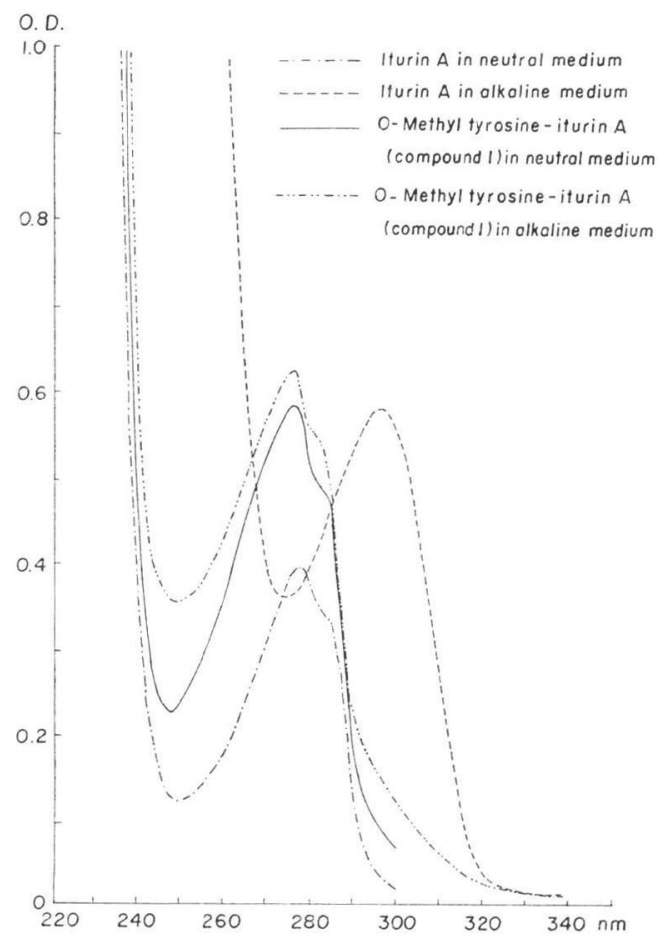

Table 2. Percent of growth inhibition, after 8 hours, of Micrococcus luteus in liquid medium (deduced from the growth curve determined with $5 \%$ accuracy).

\begin{tabular}{l|r|r|r}
\hline \multirow{2}{*}{ Compound } & \multicolumn{3}{|c}{ Concentration of antibiotics } \\
\cline { 2 - 4 } & $20 \mu \mathrm{g} / \mathrm{ml}$ & $60 \mu \mathrm{g} / \mathrm{ml}$ & $200 \mu \mathrm{g} / \mathrm{ml}$ \\
\hline Iturin A & 42 & 73 & 100 \\
I & 10 & 20 & 47 \\
II & 3 & 30 & 73 \\
III & 25 & 31 & 45 \\
IV & 12 & 23 & 40 \\
\hline Mycosubtilin & 55 & 79 & 100 \\
V & 0 & 3 & 48 \\
VI & 6 & 22 & 54 \\
VII & 8 & 16 & 63 \\
VIII & 17 & 46 & 76 \\
\hline Bacillomycin L & 40 & 70 & 100 \\
IX & 35 & 60 & 95 \\
X & 8 & 32 & 80 \\
XI & 4 & 17 & 64 \\
\hline
\end{tabular}


inhibition reported were determined 8 hours after the addition of antibiotic.

\section{Results}

\section{Characterization of Antibiotic Derivatives}

The substitution of hydroxyl groups and carboxylic groups gave compounds with more lipophilic properties. The rate of migration of the derivatives on thin-layer plates increases with the number or substituting groups and thin-layer chromatography was used for the purification of the derivatives and for the estimation of the number of substituted polar groups.

The Rf of methyl and acetyl derivatives of antibiotics are shown in Table 1.

The substitution of phenolic group of tyrosine was confirmed by U.V. spectra. Fig. 4 shows U.V. spectra of iturin A and tyrosine-O-methyl derivative of iturin A in neutral and alkaline solution. Fig. 5 shows U.V. spectra of iturin A and of acetyl derivatives of iturin A.

In neutral solution, iturin $\mathbf{A}$ gives an absorption maximum at $278 \mathrm{~nm}(\epsilon=1,600)$. The wavelength of the maximum is shifted in alkaline solution and the molecular extinction coefficient is increased $\left(\lambda_{\max }=295 \mathrm{~nm}, \epsilon=2,400\right.$ ). When the phenolic group of the tyrosine is methylated, the derivative (I) exhibits an increase of molecular extinction coefficient but no shift of the absorption maximum in alkaline solution $\left(\epsilon_{\max }=278 \mathrm{~nm}, \epsilon=2,400\right)$. The acetylation of the phenolic group eliminates the absorption band at $278 \mathrm{~nm}$, thus it is possible to distinguish the O-acetyl-tyrosine derivative (II) from the $\mathrm{O}$-acetyl-serine derivative (III) of iturin $\mathrm{A}$.

\section{Antibacterial Activity of Antibiotic Derivatives}

The inhibitory effect on the growth of M. luteus in liquid medium with various concentrations of compounds is given in Table 2 .

\section{Discussion}

The antibacterial activities of iturin A, mycosubtilin and bacillomycin $\mathrm{L}$ are quite similar: 70 $80 \%$ inhibition of the growth is observed at $60 \mu \mathrm{g} / \mathrm{ml}$ and a total inhibition at $200 \mu \mathrm{g} / \mathrm{ml}$. The inhibitory effect of each derivative is much less than that of its parent antibiotic. This diminution of the inhibitory effect is specially important for the low concentrations: at $20 \mu \mathrm{g} / \mathrm{ml}$ the inhibition is $40 \sim 55 \%$ with natural antibiotics and strongly diminished $(0 \sim 35 \%)$ for derivatives. It seems, from these data, that both the tyrosine phenolic group and the serine hydroxyl group of iturin $\mathrm{A}$ and mycosubtilin are essential for the maximum antibacterial activity. However the comparison of quantitative results does not allow to establish close connections between the nature of substituting groups and the percentage of inhibition. In the case of bacillomycin $\mathrm{L}$ the esterification of carboxylic groups does not strongly modify the antibacterial action.

Antibiotics of iturin group are structurally related and they have a hydrophobic moiety: the hydrocarbon chain of the $\beta$-amino acid, and a hydrophilic moiety: the peptidic cycle. The presence of polar groups, hydroxyl and phenolic groups in the side chains of amino acids constituting the peptidic moiety seems to be a necessary condition for antibacterial activity but the position of polar groups in the peptide might have an importance for the antibiotic action. Recent NMR studies have given some informations upon the conformation of iturin $\mathrm{A}^{12}$. The molecule is locked by two hydrogen bonds which allow a large freedom to the side chain of the tyrosine residue and block the side chain of serine residue. This steric hindrance gives an explanation to the difficulty in the acetylation of hydroxyl group of the serine.

Our present data show the importance of polar groups in the antibacterial activity of the antibiotics of iturin group. Investigations on the three dimensional structures of these antibiotics should 
give more informations on the role of the amino acid side chains in the antibacterial action.

\section{Acknowledgements}

This work was supported by the Délégation Générale à la Recherche Scientifique (contrat $\mathrm{n}$ 77.7.0491) and the Centre National de la Recherche Scientifique (A.I. n 031201).

\section{References}

1) Delcambe, L.: Iturine. I. Préparation, purification et poids moléculaire. Bull. Soc. Chim. Belg. 74: $315 \sim 328,1965$

2) Walton, R. B. \& H. B. Woodruff: A crystalline antifungal agent, mycosubtilin, isolated from subtilin broth. J. Clin. Invest. 28: 924 926, 1949

3) Landy, M.; G. H. Warren, S. B. Roseman \& L. G. Colio: Bacillomycin, an antibiotic from Bacillus subtilis active against pathogenic fungi. Proc. Soc. Exp. Biol. \& Med. 67: 539 541, 1948

4) Peypoux, F.; M. Guinand, G. Michel, L. Delcambe, B. C. Das \& E. Lederer: Structure of iturin A, a peptidolipid antibiotic from Bacillus subtilis. Biochemistry 17: 3992 3996, 1978

5) Peypoux, F.; G. Michel \& L. Delcambe: Structure de la mycosubtiline, antibiotique isolé de Bacillus subtilis. Eur. J. Biochem. 63: 391 398, 1976

6) Besson, F.; F. Peypoux, G. Michel \& L. Delcambe: Structure de la bacillomycin L, antibiotique de Bacillus subtilis. Eur. J. Biochem. 77: 61 67, 1977

7) Peypoux, F.; M. Guinand, G. Michel, L. Delcambe, B. C. Das, P. Varenne \& E. Lederer: Isolement de l'acide 3-amino 12-méthyl tétradécanoïque et de l'acide 3-amino 12-méthyl tridécanoïque à partir de l'iturine, antibiotique de Bacillus subtilis. Tetrahedron 29:3455 3459, 1973

8) Delcambe, L. \& R. Devignat: L'iturine, nouvel antibiotique d'origine congolaise. Acad. Roy. Sci. Coloriales 6: 1 77, 1957

9) Besson, F.; F. Peypoux, G. Michel \& L. Delcambe: Mode of action of iturin A, an antibiotic isolated from Bacillus subtilis, on Micrococcus luteus. Biochem. Biophys. Res. Commun. 81: 297 304, 1978

10) Bessov, F.; F. Peypoux \& G. Michel: Action of mycosubtilin and of bacillomycin L on Micrococcus luteus cells and protoplasts. Influence of the polarity of the antibiotics upon their action on the bacterial cytop asmic membrane. FEBS Letters 90: 36 40, 1978

11) Irmscher, G.; G. Bovermann, G. Boheim \& G. Jung: Trichotoxin A 40, a new membrane-exciting pepticle. Part A. Isolation, characterization and conformation. Biochim. Biophys. Acta 507: 470 484, 1978

12) Garbay-Jaurequiberry, C.; B. P. Roques, L. Delcambe, F. Peypoux \& G. Michel: Nmr conformational study of iturin A, an antibiotic from Bacillus subtilis. FEBS Letters 93: 151 156, 1978 